\title{
MOTIVATION AND COGNITIVE LEARNING IN WORKPLACES OF VIETNAMESE STUDENTS IN LEARNING CHINESE: A QUALITATIVE STUDY
}

\author{
Kieu Quan Thuan and Wei-Te Liu \\ Department of Technological and Vocational Education, National Yunlin University of Science and Technology, \\ Taiwan, R.O.C \\ E-mail: kieuquan4438@gmail.com
}

\begin{abstract}
In language learning, besides suitable learning strategies, motivation plays as the motor to encourage learners to walk toward their desired plans. Moreover, learning cognition in workplaces is considered as good strategies for language learning in off-classrooms. To comprehend the learning motivation and learning cognition in workplaces of language learners, this study aims to explore the motivation's components and learning cognitions in workplaces of Chinese learners. Five Vietnamese students, who had studied Chinese at least for six months, were subjects of the study. Interviews and diary note-takings were used as the instruments for data collection. Data were analyzed through a descriptive analysis and coding categories. The obtained results showed that there are three major factors of motivation's components for participants to learn Chinese: (1) communicative purpose, (2) interest in culture and (3) promotion of future career. Moreover, in term of cognition of Chinese usage in workplaces, obtained results showed that the cognition of participants in two key procedures: knowing from problem-solving and reasoning and knowing from association with people in their workplaces.
\end{abstract}

Keywords: motivation, Chinese learning, learning cognition, Vietnamese students, workplaces

\section{INTRODUCTION}

Learning a second language is indicated as the involved process of individuals to economic, culture and individual interested factors. Considering the recent tremendous development of the economy and long-standing culture, Chinese has been the concerned language for many people, especially those who want to do trades with Chinese or who want to understand Chinese culture. Hence, it is recently known that Chinese has become the most growing study language in many parts of the world [1].

Learning Chinese is like learning other second languages. To be successful, besides learning styles, teacher leadership, and teaching intensity, learners need high motivation in order to be focused and persisted to the targeted goals [2]. Factors build up motivation are highly related to the living environment, workplaces and study situation. Thus, learners are likely to be different in components of motivation in language. Communicative purpose and cognitive development are two major keys which energize learners to go forward to their planned ambitions in learning a second language.

Moreover, learning a second language is similar to learning many other fields in which learners not only study in school but also from off-school environments, such as learning in workplaces [3]. In addition, there are three aspects of cognition in workplace learning. The three are workplace information literacy, knowledge management and the relationship between information behavior and innovation processes [4]. Accordingly, the first aspect is indicated as the basic language sufficiency, and the second aspect is highly related to the organization of language in particular tasks. The third aspect is the knowing getting from problem-solving and reasoning in using a language.

In this study, in order to comprehend properly the motivation based learning and cognition-based in workplaces in language learning, this study focuses on exploring the motivation's components of Vietnamese in learning Chinese and their learning cognition in usage Chinese in their workplaces. The major points of the study aim to answer the following 
questions: (1) what are the factors build up the components of motivation for learning Chinese of Vietnamese students at Yuntech; (2) how are the learning cognitions of Vietnamese students in bolstering their Chinese skills in their workplaces?

On the proposed scales of study purpose, in order to make it easy to understand the purpose of research, this part of the article structurally introduces theories and previously studied related to motivation based learning and learning cognition based workplace as the framework for the template findings.

\section{Perspectives of Motivation}

Oxford dictionary defines motivation is the reason or reasons for acting or behaving in particular ways. Similarly, Guay et al. [5] suggest that motivation refers to the reasons underlying behavior. Gredler in Broussard and Garrison [6] broadly define motivation as the attribute that moves a person to do or not to do something. In collaborating for that Maslow [7] stated that motivation is the ambition to pursue needed things, both materials and spiritual things, such as materials, safety, love, selfesteem, and self-actualization.

In detail, the Vroom expectancy motivation theory identified motivation as the habitual activities of individuals for achieving desired goals, and the levels of habitual activities in a particular manner depending on the intensity of expected goals. Accordingly, there are three main elements which represent the habitual activities, expectancy, instrumenttality, and valance. Expectancy is the acceptance in the relationship of cause and effect of actions, and it is the desired outcome for planned activities, while instrumentality is indicated as the faith of expected outcome of certain performance, and valance is considered as the value of expected achievement of individuals.

Moreover, motivation is classified into two major groups, integrative or instrumental motivation, and extrinsic or intrinsic motivation. In language learning, integrative motivation is related to the personal ambition of learning in order to be able to communicate with people in groups or communities, while instrumental motivation relates to social and economic targets [8]. Modifying for that, Brown [9] explained that learners often build up their motivations with mixed factors of intention of both communication and socialeconomic purpose.

To illustrate about intrinsic or extrinsic motivation, Noels et al. [10] argued that intrinsic motivation is something from the personal desire of learners, or it is the selfdetermination of learning without any impact of outside factors [11]. Differently, extrinsic motivation is viewed as factors external individuals, and they force or stimulate individuals to act for learning [12]. Extrinsic motivation is the outside sources which work as the determined motor to drive one to learn to achieve a certain goal.

In conclusion, motivation, in language learning, is the motor that stimulates acts for achieving the planned goals of the study, and motivation plays as the determination in helping to concentrate on the desired goals until they are achieved. Motivation is divided into groups, integrative or instrumental group, and an intrinsic or extrinsic group. Intrinsic motivation is related to communicative purpose, while instrumental one is regarding social-economic desire. Differently, extrinsic motivation is related to external factors which force learners to act to develop skills connected to language learning, while the intrinsic factor is indicated as the personal desire in learning a language. Additionally, many factors work together as motivations for learners to learn a language.

Webster dictionary defines cognition is the cognitive mental process, while Cambridge dictionary explains that cognition is the mental action for acquiring the knowledge and understanding through thinking, experience, and senses. To modify, Newell [13] provided cognition into criteria for a better 
comprehension of it. All the criteria are related to the mental process of individuals, such as flexible behavior, real-time performance, adaptive behavior, vast knowledge base, dynamic behavior, knowledge integration, natural language, learning, development, evolution, and brain realization.

More clearly, Salazar stated that cognition processes include a number of mental activities which are represented by two kinds of cognitive process, sensation, and perception. A sensation is comprehensive as the input of information from the external environment, and it is simply the process of intake of information without the analysis process. On the other hand, perception is understood as the continuing process for adaptation and analysis of receiving information of sensation.

Salazar also modified that our daily mental activities, such as thought and learning, are the processes of cognition. To have a precise view of that, Salazar explained that thought is related to problem-solving, decisionmaking, creative thinking, and reasoning, and its work is various in tasks, with the two major steps, analysis and comparison. Firstly, the perception analyzes the input objects and then compares the filtered information to the formed concepts to comprehend the input objects.

In term of learning, Greeno et al. [14] understood cognitive learning into three aspects, knowing as having an association, knowing as concepts and cognitive abilities and knowing as distributed in the world. Knowing as having association is the learning from experience gained from task analysis or network of activities. Knowing as concepts and cognitive abilities is the scale of cognition learning in term of recognition and reconstruction of the concepts in order to have a better comprehension about learning or working, and this term of knowing is related to reasoning and problem-solving. Knowing as distributed in the world is the term of learning from the communication and integration with external objects, such as books, artifacts, and people.

\section{METHOD}

The study employed five Vietnamese students, doing their graduate studies at the Faculty of Management of National Yunlin University of Science and Technology, as the research participants. These five students were selected out from total twelve Vietnamese students who were learning Chinese at Yuntech University with a stratified random method. Among them, one was pursuing his doctoral program majoring in Finance and the other four students were doing their master programs majoring in international management business administration (IMBI). Additionally, among them, Linh was female, while the other four students were male. Additionally, they all obtained the intermediate level of Chinese proficiency.

The age of participants ranged from 23 to 31 , with the mean of 25 . Linh was 23 years old, and Tuan was 24 years old. They both had learned Chinese for more than one year, and they both moonlighted as teachers to teach Vietnamese to local people who have their sons got married to Vietnamese women. Linh and Tuan obtained the intermediate level of Chinese skills. Trung was 31 years old, and he was proficient in spoken Chinese. The rest of the participants, Nam and Tung, were 24 and 25 years old respectively. Trung, Nam, and Tung worked as store-sellers in their leisure times.

A qualitative approach was hired as the methodology for getting data for the study, with semi-structured interviews and diary notes conducted as the major instruments for getting responses from the participants. At first, participants were invited to join the study by email, and a suitable time was set up for each participant to join the interviews. All interviews were recorded into mp3-files for the process of data analysis.

Secondly, five in-depth face-to-face interviews were conducted to get responses from participants, and all the interviews were implemented in the living rooms of school dormitories, with private environments to 
ensure participants always stay focused during the interviews. Beside of key questions which directly stimulate participants to express their opinions on what motivated them to study Chinese, many follow-up questions were put up to help participants to properly describe their ideas completely in case their answers for key questions were unclear.

Thirdly, participants were required to implement daily note-takings for one week, purposely to describe their learning cognitions when they use Chinese in workplaces. Participants were asked to describe their emotions and cognitions in using Chinese in their workplaces for each day, and the daily notes of participants were collected each day by the researcher in the evening in appointed times with participants.

In the data analysis, firstly, recorded-files were transcribed totally in English for a descriptive and narrative analysis, and then the coding process was categorized, based on their similarities and differences of participants' ideas. During this process, similar arguments were highlighted in the same colors in order to have an effective categorized process. Moreover, for the daily self-taking notes of participants, researchers also classified them into codes, based on the similar perspectives of participants. All coded data were used to describe the cognition in using Chinese of participants.

\section{RESULTS AND DISCUSSION}

On the grids of this preliminary study on learning motivation and learning cognition in workplaces of Vietnamese students, the achieved data showed major responses which satisfied the proposed scales of learning purpose. Accordingly, the obtained data showed that there are three main factors build up the components for participants to learn Chinese, communicative purpose, interest in Chinese culture and promotion of future career. Moreover, in term of learning cognition based workplace, obtained results showed two cognitive ways for enriching their Chinese skills: getting to improve their Chinese skills by problem-solving and reasoning and developing their Chinese skills as distributed with communication.

All interviewees emphasized the importance of learning Chinese during their lives in Taiwan, and there were three major scales of findings highlighted: communicative purpose, interest in culture and promotion of future career. On the scale of communicative purpose, interviewees stated that learning Chinese provides them with essential skills for doing their daily activities which mostly required basic skills of Chinese. In detail, interviewees asserted that because of lacking Chinese proficiency, they had encountered difficulties when they went shopping, went out for eating and went out. Therefore, they decided to learn Chinese in order to be able to interpret into Taiwanese community easily. Three participants worked part-time as store-sellers, and they were required to be able to communicate with customers. Thus, they came up with the decision to study Chinese to strengthen their Chinese spoken skills. Moreover, two other participants informed that they moonlighted as teachers to teach Vietnamese to local inhabitants. Therefore, they viewed the necessity to bolster their Chinese skills in order to express and describe their ideas to students effectively and properly.

On the scale of their interest in Chinese culture, participants showed a strong connection between their passions of Chinese traditional letters and ancient poems and learning motivation. Participants expressed that many ancient books in their country were written down used traditional Chinese letters, so learning Chinese is the way to enable them to read those ancient books. Moreover, almost all participants emphasized their interest in directly comprehend the contents of ancient Chinese poems which mostly written down by using traditional Chinese, so learning Chinese provides them precious opportunity to fulfill their interest. 
Moreover, interviewees also said that they aim to utilize Chinese for their future careers, so they tried to study Chinese to perfect their skills. Some participants plan to be Chinese teachers after they complete their studies in Taiwan, so they desired to bolster their Chinese proficiency during their stays in Taiwan. Others viewed that Chinese people recently strongly invested into Vietnam, and this provides a great chance for those who can speak Chinese well to get jobs in Chinese companies; thus, learning Chinese in Taiwan is kind of useful activities for their future careers.

In Summary, there were numerous factors build up the determination and persistence for Vietnamese students to study Chinese. However, based on the modes of similarities and differences, there were three main factors work as the stimulants for Vietnamese students to learn Chinese in Taiwan. The three factors are the communicative purpose, interest in culture and future career.

With grids of responses of participants related to learning cognition in the workplace, there are two key solutions adopted by participants in order to bolster their Chinese skills, learning from problem-solving and reasoning and learning from association with people in their workplaces.

In term of learning from problem solving and reasoning, participants who worked as store-sellers explained that their tasks were nothing but communicated with customers. At first, their spoken Chinese was weird and incorrectly pronounced; hence, customers could not understand their expressions properly. After that, they tried to correct their incorrect pronunciations in order to communicate well with customers. Also, participants who moonlighted as store-sellers told that they were often required to read the list of items mostly in Chinese. At first, they often made mistakes in doing the input of the names of items into computers. To improve, they tried to recognize words for avoiding doing mistakes for the next times. Some participants, worked as teachers to teach Vietnamese, proclaimed that they often spoke Chinese weirdly since their pronunciations were incorrect, and they strengthened their spoken Chinese with the help from their students. Furthermore, they have to use Chinese to illustrate the meanings of Vietnamese words. They often made mistakes in spelling and grammars for the first period of their works. However, they gradually corrected these mistakes with the help of their students.

In term of learning from association with people in the workplace, participants emphasize the important role of communication in the process of strengthening their Chinese skills. Al participants claimed that observing and copying the ways of using words and building up the sentences of native Taiwanese was effective to strengthen their Chinese speaking skills. Participants worked as sellers said that they often talked with their Taiwanese colleagues in break-times, and through talking with their colleagues, they tried to copy the ways of speaking and using words of their colleagues. This method was helpful to bolster their intonations and ways of using words in speaking in order to express their ideas effectively. Similarly, participants worked as teachers to teach Vietnamese stated that they were able to strengthen their usages of words as well as the intonations in spoken Chinese through interaction with their students in classrooms.

To discuss the motivating factors which encouraged participants to study Chinese, the study highlighted three major factors built up the components of motivation for Vietnamese to study Chinese in Taiwan, the communicative purpose, interest in Chinese culture and promotion for future careers. The study showed the learning motivations of learners were from various factors, yet there is no single factor found out influence the participants' motivation in learning Chinese. Generally, motivations in learning Chinese of Vietnamese students were combined of instrumental and integrative as well as combined of intrinsic and extrinsic factors, and the obtained results are highly 
linked to the works of Tony Lai [15] and Galishnikova [16].

Similar to the learning cognition in workplace theory of Greeno et al. [14] the achieved data emphasized on two major kinds of learning cognition in workplaces of Vietnamese students, learning from problemsolving and reasoning and learning from distribution to the world. In learning from problem-solving and reasoning, participants highlighted the knowledge gained through the process of correction and innovation of mistakes, while in the aspect of learning from distribution to the world, the learners put the pressure on the effect of communication with partners or friends or natives for enhancement of language proficiency.

For the purpose of design, the study employed the qualitative methodology, with interviews and self-observation notes as the instruments for data collection, and the sample size was small. The scales of findings should be more varied if the objectives of this study are carried out with a larger number of participants or with the quantitative approach.

\section{CONCLUSION}

On the grids of findings, the study found out that living and working situation play as the motivating factors which generated the determination and persistence in learning Chinese of participants. In accordance with the findings, learners' proportion of motivation often comes from combined components, the combined one of the integrative/instrument or intrinsic/extrinsic or the mixed one of many of those. Furthermore, the study confirmed the essential role of two kinds of learning cognition in workplaces in the theory of Greeno et al. [14] learning from problem-solving and reasoning and learning from distribution to the world.

On the relevance of the findings, researchers would suggest the need of knowing the living and working situation of language learners in order to help them to have high motivation in learning. Moreover, the learning process is not only available in the classrooms but also in workplaces and social activities. Therefore, providing effective guidance on how to enrich language skills in off-classrooms environments, such as workplaces, should be concerned as the important teaching materials for language teachers in order to help their students to bolster language proficiency outside classrooms.

\section{REFERENCES}

[1] Y. Hao, J.-C. Hong, J.-T. Jong, M.-Y. Hwang, C.-Y. Su, and J.-S. Yang,. "NonNative Chinese Language Learners' Attitudes towards Online Vision-Based Motion Games" Br. J. Educ. Technol., vol. 41, no. 6, pp. 1043-1053, 2010.

[2] D. Sulistiyarini and S. Sukardi, "The Influence of Motivation, Learning Styles, Teacher Leadership, and Teaching Intensity on Students'leaning Outcomes," J. Pendidikan Teknologi dan Kejuruan., vol. 23, no. 2, pp. 136-143, 2016.

[3] S. Billett, Learning in the Workplace: Strategies for Effective Practice. St Leonards: Allen \& Unwin, 2001.

[4] L. Middleton, H. Hall, and R. Raeside, "Applications and Applicability of Social Cognitive Theory in Information Science Research,” J. Librariansh. Inf. Sci., May 2018.

[5] F. Guay, J. Chanal, C. F. Ratelle, H. Marsh, S. W., Larose, and M. Boivin, "Intrinsic, Identified, and Controlled Types of Motivation for School Subjects in Young Elementary School Children," Br. J. Educ. Psychol., vol. 80, no. 4, pp. 711-735, 2010.

[6] S. C. Broussard and M. E. B. Garrison, "The Relationship between Classroom Motivation and Academic Achievement in Elementary School-Aged Children," Fam. Consum. Sci. Res. J., vol. 33, no. 2, pp. 106-120, 2004.

[7] A. Maslow, The Theory of Human Motivation. Digitalized by Watchmaker Publishing. Oregon: Rough Draft Printing, 2003.

[8] J. Norris-Holt, "Motivation as a Contributing Factor in Second Language 
Acquisition," Internet TESL J., vol. 7, no. $6,2001$.

[9] H. Brown, Principles of Language Learning and Teaching. Englewood Cliffs NJ: Prentice-Hall, 2000.

[10] K. A. Noels, R. Clement, and L. G. Pelletier, "Intrinsic, Extrinsic, and Integrative Orientations of French Canadian Leamers of English," Can. Mod. Lang. Rev., vol. 57, no. 3, pp. 424442, 2001.

[11] T.-I. Pea, "Second Language Orientation and Self - Determination Theory: A Structural Analysis of the Factors Affecting Second Language Achievement," J. Lang. Soc. Psychol., vol. 27, no. 1, pp. 5-27, 2008.

[12] F. David, "Motivation in the Second Language Classroom: The Importance of Moving from Extrinsic to Intrinsic Motivation”. Arkansas, 2015.
[13] A. Newell, "Physical Symbol Systems*". Cogn. Sci., vol. 4, no. 2, pp. 135-183, 1980.

[14] J. Greeno, A. M. Collins, and L. Resnick, "Cognition and learning," in Handbook of Educational Psychology, New York: Macmillan, 1996.

[15] H. Tony Lai, "The Motivation of Learners of English as a Foreign Language Revisited," Int. Educ. Stud., vol. 6, no. 10, pp. 90-101, 2013.

[16] E. M. Galishnikova, "Language Learning Motivation: A Look at the Additional Program," Procedia - Soc. Behav. Sci., vol. 152, pp. 1137 - 1142, 2014. 